\title{
Clozapine, Fluoxetine, and Benztropine- associated lleus: Case Report
}

\author{
Pegah Pajouhi M.D. (PGY1) \\ Stanford University, pegahpajouhi@yahoo.com
}

James A. Bourgeois O.D., M.D.

University of California, Davis, james.bourgeois@ucdmc.ucdavis.edu

Follow this and additional works at: https://jdc.jefferson.edu/jeffjpsychiatry

Part of the Psychiatry Commons

Let us know how access to this document benefits you

\section{Recommended Citation}

Pajouhi, Pegah M.D. (PGY1) and Bourgeois, James A. O.D., M.D. (2007) "Clozapine, Fluoxetine, and Benztropine- associated Ileus: Case Report," Jefferson Journal of Psychiatry. Vol. 21 : Iss. 1 , Article 1. DOI: https://doi.org/10.29046/JJP.021.1.001

Available at: https://jdc.jefferson.edu/jeffjpsychiatry/vol21/iss1/1

This Article is brought to you for free and open access by the Jefferson Digital Commons. The Jefferson Digital Commons is a service of Thomas Jefferson University's Center for Teaching and Learning (CTL). The Commons is a showcase for Jefferson books and journals, peer-reviewed scholarly publications, unique historical collections from the University archives, and teaching tools. The Jefferson Digital Commons allows researchers and interested readers anywhere in the world to learn about and keep up to date with Jefferson scholarship. This article has been accepted for inclusion in Jefferson Journal of Psychiatry by an authorized administrator of the Jefferson Digital Commons. For more information, please contact: JeffersonDigitalCommons@jefferson.edu. 


\title{
Clozapine, fluoxetine, and benztropine- associated ileus: Case report
}

Pegah Pajouhi, M.D. (PGY1), James A. Bourgeois, O.D., M.D.

\begin{abstract}
Gastrointestinal complications of anticholinergic medications are prevalent, potentially life-threatening, and could be more actively prevented. We present a case report of an ileus that required surgical intervention and developed in the context of clozapine, benztropine, and fluoxetine use. The case exemplifies the potential anticholinergic toxicities of clozapine and benztropine as well as possible pharmacokinetic interactions between fluoxetine, clozapine, and benztropine. We discuss ways to minimize the likelihood of anticholinergic complications with these medications.
\end{abstract}

\section{CASE REPORT}

A 50-year-old schizophrenic man presented with diffuse abdominal pain radiating to his flanks, cramping, green emesis, and no bowel movements for three days. Outpatient medications included clozapine $200 \mathrm{mg} \mathrm{q} \mathrm{AM}$ and $400 \mathrm{mg}$ qhs, benztropine $2 \mathrm{mg}$ bid, and fluoxetine $20 \mathrm{mg}$ q AM. He had a history of smoking one and one-half packs of cigarettes daily for 35 years. His abdomen was tender in the right lower quadrant and was distended and tympanic; bowel sounds were hypoactive. Dilated large bowel loops were visible in abdominal plain film and dilated proximal bowel was noted on CT scan. His treatment team was unable to resolve the small bowel obstruction through bowel rest and decompression. Therefore, exploratory laparotomy was performed. Surgery revealed a massively dilated jejunum with a clear transition point to decompressed distal bowel; no mechanical source of obstruction was identified.

He remained off his medications until post-op day 2, at which time he was re-started on fluoxetine $20 \mathrm{mg} \mathrm{q} \mathrm{AM}$ and benztropine $2 \mathrm{mg}$ bid. Clozapine $200 \mathrm{mg}$ q AM and $400 \mathrm{mg}$ qhs was re-started on post-op day 6. On post-op day 12, the Psychiatric Psychosomatic Medicine (PSM) Service evaluated the patient. The PSM Service noted the possibilities of a pharmacokinetic clozapine-fluoxetine drug interaction (inhibition of clozapine metabolism by 
concurrent fluoxetine) and/or a pharmacodynamic clozapine-benztropine drug interaction (both agents have significant anticholinergic effects) causing or exacerbating the ileus through an anticholinergic mechanism. Recommendations to discontinue clozapine and benztropine then to start quetiapine $200 \mathrm{mg}$ q AM and $400 \mathrm{mg}$ qhs were implemented. Serum clozapine levels were not available. On post-op day 15, the patient reported relief of abdominal pain and had reduced abdominal distension. He was transferred to a psychiatric facility.

\section{DISCUSSION}

Clozapine is an atypical antipsychotic that is an antagonist at numerous receptors: it is anti-serotonergic (5-HT2, 5-HT3), anti-alpha 1 adrenergic, antihistaminic (H1), and antimuscarinic. Its potent preferential blockade of dopamine D1 and D4 receptors are likely significant contributors to its antipsychotic effects (1). Clozapine produces a dose-dependent increase in anticholinergic activity and is primarily hepatically metabolized by $\mathrm{P} 450$ 1A2 with additional secondary pathways (2). If used concurrently with clozapine, fluoxetine and fluvoxamine increase the risk of developing anticholinergic effects; these medications increase clozapine levels by $50 \%$ and three- to four-fold, respectively, due to inhibition of P450 1A2, 2C9/19, 2D6, and 3A4. Caffeine consumption may increase clozapine levels (by inhibiting P450 1A2), while smoking may decease clozapine levels (by induction of P450 1A2) (3).

Gastrointestinal effects associated with clozapine include constipation, gastric outlet obstruction, prolonged postoperative ileus, and peritonitis with bowel perforation; fatalities have been reported $(1,4-10)$. The prevalence of developing intestinal side effects, ranging from constipation to bowel perforation, while taking clozapine has been reported as high as 33\% (5-7).

The significant anticholinergic effects of benztropine, commonly prescribed for EPS, may be especially important when added to the anticholinergic effects of clozapine. There have been reported cases of intestinal dysmotility attributed to benztropine alone as the primary anticholinergic agent (11-13). Minzenberg et al. have produced a useful table of the relative anticholinergic potencies of various psychotropic agents (14). Their table includes both a "pharmacological index" (based on published in vitro studies of muscarinic antagonism) and a "clinical index" (based on clinician ratings of anticholinergic side effects). For both indices, benztropine is given a value of 1 . Clozapine is among the most anticholinergic of the atypical antipsychotics; it has a "pharmacological 
index" of $8 \mathrm{mg}$ clozapine as the anticholinergic equivalent of $1 \mathrm{mg}$ benztropine and a "clinical index" of $85 \mathrm{mg}$ clozapine as the anticholinergic equivalent of $1 \mathrm{mg}$ benztropine (14). Using the table of Minzenberg et al., we find that our patient initially had a combined anticholinergic effect totaling 79 benztropine equivalents by the "pharmacological index" and 11 by the "clinical index"; after clozapine and benztropine were discontinued and quetiapine was started, the patient received only 0.8 benztropine equivalents by the "pharmacological index" and 2.6 by the "clinical index" (14).

Long-term, treatment-refractory psychiatric inpatients have additional risk factors for developing an ileus. One factor is the compounding effect of a long history of high-dose antipsychotic medication that leads to reduced bowel motility. A second factor is the reduction of daily physical activity levels among patients living in long-term inpatient psychiatric facilities. At the Atascadero State Hospital in California, for instance, where 60\% of patients on clozapine were found to have constipation, the staff implemented the Clozapine Constipation Protocol in 1995 (8). The protocol involves abdominal imaging and physical assessment prior to starting the medication, slow dosage increases (maximum of $100 \mathrm{mg} /$ day each week), daily documentation of bowel and dietary habits, and input from a dietitian who encourages a high-fiber diet, adequate fluid intake, and regular physical exercise. Most of the patients on clozapine receive a stool softener or a bulkforming laxative, and some are prescribed bethanechol. Taking these measures resulted in a significant decline in both the prevalence of constipation and the number of patients transferred to the medical unit for the treatment of clozapine-induced gastrointestinal dysmotility (8).

We offer the following five suggestions to avoid adverse bowel events in patients on clozapine and/or benztropine: 1) increased surveillance for bowel dysfunction in patient receiving the medications 2) proactive management of early bowel dysmotility to prevent serious outcomes 3) avoidance of both pharmacodynamic and pharmacokinetic drug-drug interactions that increase anticholinergic effects of clozapine (specific avoidance of fluoxetine, fluvoxamine, or benztropine with clozapine) 4) use of alternative atypical antipsychotic medications with lower degrees of anticholinergic activity in patients at higher risk of bowel dysmotility and 5) avoidance of benztropine in patients who have had clinical sings of decreased intestinal motility. When clozapine is necessary despite a history of clozapine-induced ileus (e.g. in patients who are resistant to other medications), clinicians may try the following after the patient has fully recovered gastrointestinal motility: 
1) restart clozapine at a lower dose while continuing to avoid fluoxetine, fluvoxamine, and benztropine; or 2) cautiously increase the clozapine dose while continuing to avoid these other agents. When possible, monitoring of serum clozapine levels may help.

\section{SOURCE INFORMATION}

From the Department of Psychiatry and Behavioral Sciences, Stanford University School of Medicine, Stanford, CA (PP) and the Department of Psychiatry and Behavioral Sciences, University of California, Davis, Sacramento CA 95817 (JAB). The authors would like to thank the patient for allowing his case to be presented and shared with our fellow colleagues. Please direct inquiries to James A. Bourgeois, O.D., M.D.: james.bourgeois@ucdmc.ucdavis.edu.

\section{REFERENCES}

1. Sim K, Yong TW, Liew E, Choon CH. Clozapine-associated pseudomembranous colitis: a case report and review of the literature. J Clin Psychopharmacol 2006; 26(1):89

2. Chew ML, Mulsant BH, Pollock BG, Lehman ME, Greenspan A, Kirshner MA, Bies RR, Kapur S, Gharabawi G. A model of anticholinergic activity of atypical antipsychotic medications. Schizophr Res 2006; 88(1-3): 63-72

3. Sandson NB, Armstrong SC, Cozza KL. Med-Psych drug-drug interactions update: An overview of psychotropic drug-drug interactions. Psychosomatics 2005; 46(5):464-494

4. Levin TT, Barrett J, Mendelowitz A. Death from clozapine-induced constipation: case report and literature review. Psychosomatics 2002; 43(1):71-73

5. de Leon J, Odom-White A, Josiassen RC Diaz FJ, Cooper TB, Simpson GM. Serum antimuscarinic activity during clozapine treatment. J Clin Psychopharmacol 2003; 23(4):336-341

6. Drew L, Herdson P. Clozapine and constipation: a serious issue. Aust N Z J Psychiatry 1997; 31(1):149-150

7. Tang WK, Ungvari GS. Clozapine-induced intestinal obstruction. Aust N Z J Med 1999; 29(4): 560

8. Hayes G, Gibler B. Clozapine-induced constipation. Am J Psychiatry 1995; 152(2):298

9. Freudenreich O, Goff DC. Colon perforation and peritonitis associated with clozapine. J Clin Psychiatry 2000; 61(12):950-951

10. Townsend G, Curtis D. Case report: Rapidly fatal bowel ischaemia on clozapine treatment. BMC Psychiatry 2006; 6:43 
11. Sheikh RA, Prindiville T, Yasmeen S. Haloperidol and benztropine interaction presenting as acute gastrointestinal obstruction. Am J Gastroenterol 2001; 96(3):934-935

12. Isbister GK, Oakley P, Whyte I, Dawson A. Treatment of anticholinergic-induced ileus with neostigmine. Ann Emerg Med 2001; 38(6):689-693

13. McCormack M: Caecal rupture in psychotic patients. Br Med J 1974; 4(5936):82-83

14. Minzenberg MJ, Poole JH, Benton C, Vinogradov S. Association of anticholinergic load with impairment of complex attention and memory in schizophrenia. Am J Psychiatry 2004; 161(1):116-124 